\title{
A Simple Analyte Volatilization in Polytetrafluoroethylene (PTFE) Vessel for Spectrophotometric Determination of Boron
}

\author{
*Risna E. Y. Adu ${ }^{a)}$, Roto Roto ${ }^{\text {b) }}$ \& Agus Kuncaka ${ }^{\text {b) }}$ \\ a) Chemistry Department/Faculty of Agriculture, Universitas Timor, Kefamenanu-Indonesia \\ b) Chemistry Department/Faculty of Mathematics and Natural Sciences, UGM, Yogyakarta-Indonesia \\ Received 24 March 2021, Revised 21 April 2021, Accepted 21 May 2021 \\ doi: 10.22487/j24775185.2021.v10.i2.pp98-104
}

\begin{abstract}
A simple analyte separation through an in-situ volatilization system in a polytetrafluoroethylene (PTFE) container was carried out for boric acid analysis in a food product by spectrophotometry. Separation was conducted in two teflon containers divided into the reagents compartment (outer vessel) and sample compartment (inner vessel). System optimization was done by varying the curcumin content and ethanol: water ratio. The optimum condition of the volatilization system was achieved at a curcumin concentration of $0.1 \%$ and ethanol: water ratio of 3:1. LOD and LOQ measurements, respectively, gave a value of $0.0413 \mathrm{mg} / \mathrm{L}$ and $0.1088 \mathrm{mg} / \mathrm{L}$. The established method was used to determine boric acid content in sausage products by UV-Vis Spectrophotometry at $555 \mathrm{~nm}$. The boric acid concentration in food samples was found to be 0.913-3.518 mg/kg. The separating method through in-situ volatilization systems in a polytetrafluoroethylene (PTFE) container can be used for boric acid analysis in food samples.
\end{abstract}

Keywords: Analyte volatilization, boron, spectrophotometry, polytetrafluoroethylene vessel

\section{Introduction}

Boron is present in food mainly for two reasons: first, as a constituent element of the food, and second, borax is used as a preservative. Because of the dangerous alterations, boron can produce in the body, now the compounds of this element are entirely prohibited. Boron compounds such as boric acid and borax are not permitted to be used as food additives in Indonesia (Regulation of Health Minister Number 33 of 2012). Boric acids are known to be toxic to cells and can affect the central nervous system when consumed in excessive amounts. Ingested boron can cause a clinical symptom known as "borism" (San et al., 2001). The common symptoms from several incidents of boric acid poisoning included coughing, eye irritation, vomiting, and oral irritation (See et al., 2010). The lethal dose of boric acid, according to Litovitz et al. (1988) and See et al. (2010) is $5 \mathrm{~g}$ for fetuses, 3-6 g for infants, and 15-20 g for adults. Although the use of boric acid in foods has diminished as a result of its potential toxicity, boric acid is currently available in meatballs and tofu (Adu, 2021). Boric acid is still used as a food preservative in the country, even though it is known both to damage health and to cause fatality. Boric acid compounds are often added to several food products to control starch gelatinization, enhancing color, texture, and taste.
Kabay et al. (2010) stated that borax and boric acid are generally used as additives in starch-containing foods. Therefore, an accurate technique is needed to monitor the presence of boric acid in food products in order to provide safe food.

Boric acid measurement at minor concentrations in food samples containing complex matrix components is a fundamental problem in chemical analysis. Several sample treatments are required when the boric acid analysis method cannot provide good separation and quantification due to interference from the matrix components. Several preconcentration and separation techniques of analytes from the sample matrices prior to instrumental detection have been published. Conventional separation method of the sample matrix by esterifying boric acid with methanol to form volatile borate esters can be used, but dealing with trimethyl borate in an open laboratory is very dangerous. In addition, analyte contamination may occur due to prolonged exposure to the laboratory environment. In-situ evaporation of the matrix by isothermal distillation has been developed as an alternative separation method. The system can prevent environmental contamination of the trace impurities determination in $\mathrm{HCl}$ and $\mathrm{HF}$ (Dhavile et al., 2004), gallium arsenide (Sahayam et al., 2004), diboron trioxide (Dash et al., 2005), pure Germanium, and selenium (Ueng et al., 2004), and

*Correspondence:

Risna E. Y. Adu

e-mail: adoe.risna@yahoo.com

(c) 2021 the Author(s) retain the copyright of this article. This article is published under the terms of the Creative Commons Attribution-NonCommercial-ShareAlike 4.0 International, which permits unrestricted non-commercial use, distribution, and reproduction in any medium, provided the original work is properly cited. 
arsenic oxide (Chaurasia et al., 2002). Generally, insitu isotopic evaporation takes place in several nonsilicate containers such as polyethylene (Thangavel et al., 2005), propylene (Chaurasia et al., 2002), perfluoroalkoxy (Park \& Song, 2003), and polytetrafluoroethylene container (Dash et al., 2005). Most of the in-situ evaporation systems are applied to the inorganic matrices separation. In-situ evaporation of organic matrices in food samples is still limited. Therefore, the boric acid separation through analyte volatilization from a complex organic matrix prior to spectrophotometric boron analysis using a Polytetrafluoroethylene (PTFE) or teflon system was observed.

The in-situ volatilization system developed in this study applies a curcumin solution on the outer vessel to absorb the alkyl borate produced from the inner vessel during the esterification process. Alkyl borates in the inner vessel are produced by reacting the boric acid with alcohol. The curcumin solution on the outer vessel containing borate ester compounds after volatilization was measured using a UV-Vis Spectrophotometer at a wavelength of 555 $\mathrm{nm}$. The predefined method is then applied to boric acid analysis in sausage samples.

\section{Methods}

\section{Materials}

The materials used in the present study were curcumin, ethanol, and oxalic acid (Pro Analysis, Merck) which were used as complexes. Boric acid was used for the preparation of standard solutions. Methanol (Pro Analysis, Merck) was used as the sample solvent. Acetone (Pro Analysis, Merck) was used as the colored complex solvent in UV-Vis spectrophotometric analysis. The apparatus used in this study was a distillation chamber made of teflon, UV-Vis spectrophotometer (Spectronic 200), water bath, thermometer, $\mathrm{pH}$ meter $(H M-5 B)$, oven, analytical balance (Mettler Toledo ME204E), mortar, and number of glassware.

\section{Experiment}

Curcumin solution was prepared by dissolving $0.04 \mathrm{~g}$ of curcumin into a mixture of ethanol: water (3: 1$)$, then $0.60 \mathrm{~g}$ of oxalic acid was added. $100 \mathrm{mg}$ of boric acid was dissolved in $0.1 \mathrm{~mL}$ of methanol and put in an inner distillation vessel. Meanwhile, the $10 \mathrm{~mL}$ curcumin solution that had been prepared was poured into the outer distillation vessel. The outer distillation vessel was tightly closed and left at room temperature for 24 hours. The lid of the outer container was opened then the inner container was taken out carefully after the bottom of the inner bottle was soaked with $\sim 1 \mathrm{~mL}$ of curcumin solution. Curcumin solution was heated in a water bath at $-80{ }^{\circ} \mathrm{C}$ and diluted in $25 \mathrm{~mL}$ acetone. UV-Vis spectrophotometric measurement was carried out at the wavelength of $555 \mathrm{~nm}$ and the optimum time of complex formation (10 minutes). Curcumin concentration was varied to $0.02 ; 0.04$; $0.06 ; 0.08$ and $1 \%$. Meanwhile, the effect of the ethanol: water ratio as the curcumin solvent was studied by varying the ethanol: water ratio $(\mathrm{v} / \mathrm{v})$ at $0: 4,1: 3,2: 2,3: 1$, and 4: 0 . Food samples analysis was carried out using the same procedure at the optimum curcumin concentration and ethanol: water ratio.

\section{Results and Discussion}

\section{Volatilization chamber dimensions and materials}

The volatilization chamber for boron separation from the sample matrix was designed by using dimensions shown in Figure 1. The selected material to be used as the volatilization chamber was adjusted to the analyte that will be determined. The amount of analyte surface area involved in the reaction depends on the volume size of the sample container.

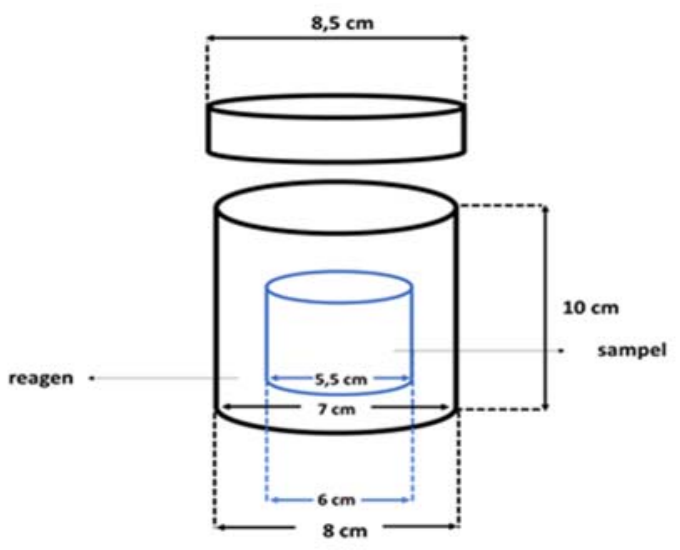

Figure 1. Volatilization chamber dimension

Therefore the dimensions and materials of the volatilization chamber play an important role in the boron-curcumin complex formation. It has been reported that the use of crucible made of quartz is superior to that of polypropylene and teflon on chloride and fluoride separation from sulfuric acid and phosphoric acid (Thangavel et al., 2005), while the polypropylene container is better than the 
routine use of platinum containers for boron analysis (the use of borosilicate chambers is not recommended for boron determination at minor concentrations due to boron contamination in the sample glassware (Crompton, 2000). Boron contamination can reduce borate esters quantity. Therefore, the volatilization chamber which is made from teflon was used (Figure 2) in this study. Chamber size was enhanced to centimeters according to its designation.

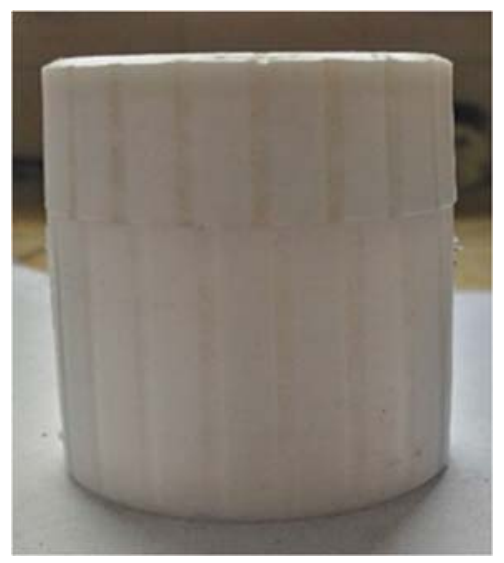

Figure 2. Volatilization chamber made of teflon

Analytical principle of in-situ volatilization system

The volatilization chamber consists of two vessels called the sample container or inner vessel and the reagent container or outer vessel. The insitu volatilization system of the analyte has a good performance. The mechanism of the system can be explained as follows: at first, an esterification reaction occurs between methanol with the boric acid contained in the sample solution to form volatile trimethyl borate in the sample container (inner vessel). The vapor pressure of trimethyl borate $\left(0.237\right.$ bar at $31{ }^{\circ} \mathrm{C}$ with bp $\left.68.7^{\circ} \mathrm{C}\right)$, which is high at room temperature, was distilled into an alcohol-containing curcumin solution in the reagent container (outer vessel). Alkyl borate is dehydrated in curcumin solution to form stable boric acid. Furthermore, the reaction scheme in the in-situ volatilization system that occurs inside water bath, according to Thangavel et al. (2004), is written as follows:

\section{$\mathrm{C}_{2} \mathrm{H}_{5} \mathrm{OH}(l)^{\text {ov }} \leftrightarrow \mathrm{C}_{2} \mathrm{H}_{5} \mathrm{OH}(v)+\operatorname{sample}(l)^{\text {iv }} \leftrightarrow$ alcoholic solution $(l)^{\text {iv }} \leftrightarrow$ alcoholic solution $(l)+\mathrm{H}_{3} \mathrm{BO}_{3}{ }^{\text {iv }}$ $\rightarrow \mathrm{B}\left(\mathrm{OC}_{2} \mathrm{H}_{5}\right)_{3}(v) \leftrightarrow \mathrm{B}\left(\mathrm{OC}_{2} \mathrm{H}_{5}\right)_{3}(l)^{\mathrm{ov}}+\mathrm{H}_{2} \mathrm{O} \leftrightarrow \mathrm{H}_{3} \mathrm{BO}_{3}(l)^{\mathrm{ov}}+\mathrm{C}_{2} \mathrm{H}_{5} \mathrm{OH}(l)^{\mathrm{ov}}$}

where the notation ' $v$ ' is vapor, 'l' for liquid, 'iv' is for the inner vessel, and 'ov' for the outer vessel.

The reaction of alkyl borate formation is a reversible reaction; thus the reaction rate depends on the medium in which the water or alkyl borate or both the product can be separated from the reaction zone. The use of an in-situ volatilization system in boron separation provides an advantage, especially in the control of methanol vapor which can affect the dissolution (when heating) from the reagent container to the sample container; thus, impurities from the reagent do not contaminate the sample. Boric acid dehydrated into curcumin solution in the reagent container specifically forms a colored boron-curcumin complex called rubrocurcumin whose red color (Dyrssen et al., 1972). Furthermore, the intensity of the complex can be measured by a UV-Vis spectrophotometer.

\section{The effect of water content}

The effect of the water content $(\mathrm{mL})$ to the volatilization system efficiency was determined by adding a volume of $0 ; 0.1 ; 0.2 ; 0.3 ; 0.4$ and $0.5 \mathrm{~mL}$. It was found that the generated alkyl borates were significantly decreased with an average reduction of $16.06 \%$ (Figure 3) for each addition of $0.1 \mathrm{~mL}$ of water. The presence of water in the system can hydrolyze alkyl borate becomes boric acid and methanol (Molinero et al., 1993). In this proposed system, the reversible reaction can inhibit the quantitative distillation of the borate esters. The more the borate esters that experience a reversible reaction, the lower the measured absorbance of the boron-curcumin complex; as a result, the sensitivity of the method became lower. Therefore the utilization of a similar system is recommended to be carried out in a water-free condition. 


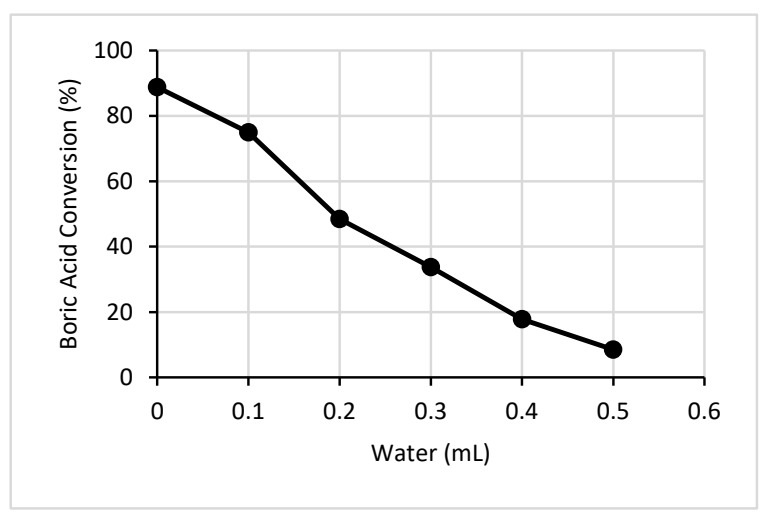

Figure 3. The effect of water content

\section{The effect of curcumin content}

The effect of curcumin concentration in the outer vessel toward the boric acid esterification occurred in the inner vessel was studied by varying the curcumin concentration to $0.02 ; 0.04 ; 0.06$; 0.08 , and $0.1 \%$.

Figure 4 depicts that the greater the curcumin concentration, the greater the boric acid conversion. The maximum boric acid conversion obtained at a curcumin concentration of $0.1 \%$ was $85.41 \%$. Hayes \& Metcalfe (1962) stated that the formation of boron-curcumin complexes is optimum when using $1.5 \%$ curcumin with a ratio of $1: 3$ for boron:curcumin. A similar volatilization system has been used to separate arsenic oxide at minor concentrations from impurities using the $\mathrm{HCl}$ reagent in the outer container. It was reported that the separation rate of the matrix decreased as the concentration of $\mathrm{HCl}$ in the outer container decreased (Chaurasia et al., 2002). In the present study, the boron-curcumin complexation was more effective at excess curcumin concentrations.

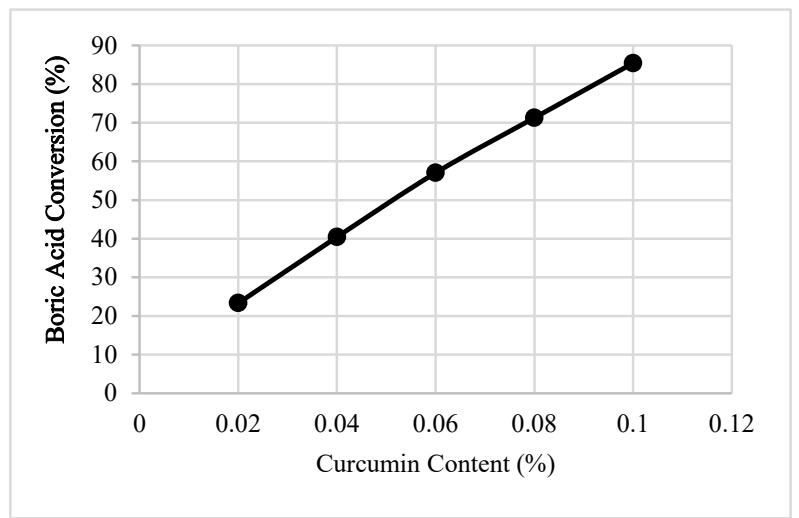

Figure 4. The effect of curcumin content

\section{The effect of ethanol: water ratio}

The ethanol to water ratio has an effect on the boric acid conversion in the in-situ matrix volatilization system. The ethanol: water ratio used to investigate the effect on the boric acid conversion was $0: 4,1: 3,2: 2,3: 1$, and 4:0. It was observed in Figure 5 that the greater the ethanol to water ratio, the greater the conversion rate of boric acid, with an average increase value of $21.89 \%$. This value proves that the amount of ethanol that is smaller and or equivalent to the amount of water that causes the alcoholic vapor to be produced is not effective enough for the borate esters formation. Conversely, the borate ester products formed in the outer vessel can be reversely hydrolyzed by the excess amount of water, as stated previously. The optimum conversion of boric acid was achieved at 3:1 ethanol:water ratio and resulted in a conversion percentage of $86.44 \%$. An ethanol ratio greater than 3:1 reduces the conversion value by $13.67 \%$. Reagents that do not contain water (at a ratio of 4:0) can reduce the dehydration rate of alkyl borate to stable boric acid. As a result, the ester product can return back to the sample container, considering that the reaction is reversible. Thangavel et al. 
(2004) suggested that the separation of boron powder containing a small amount of impurities (boric acid) could be carried out using the same matrix evaporation system with a 3:1 ethanol:water ratio.

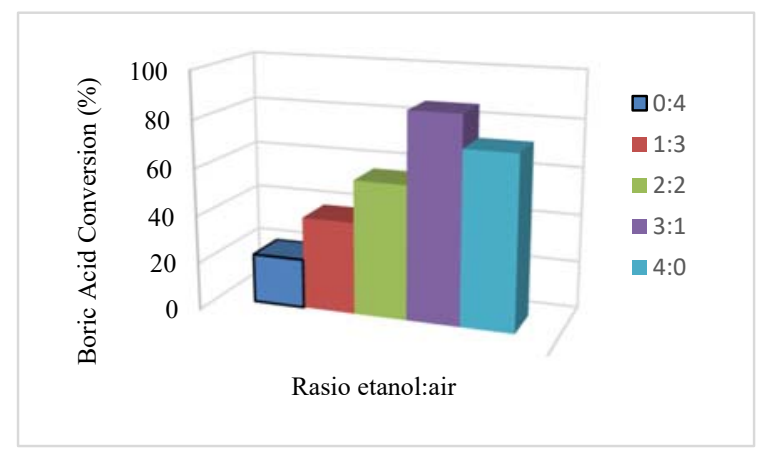

Figure 5. The effect of ethanol: water ratio

\section{$L O D$ and $L O Q$}

The limit of detection and limit of quantitation was determined by measuring the blank response seven times. The detection and quantitation limit values obtained are listed in Table 1. The detection limit value indicates that the separation method through in-situ volatilization of the boric acid is able to respond to the minimum amount of $0.0413 \mathrm{mg} / \mathrm{L}$. Meanwhile, the quantitation limit value was $0.1088 \mathrm{mg} / \mathrm{L}$, indicating that the use of the in-situ volatilization method for analyte separation was able to provide a response with acceptable or expected accuracy and precision values in the boric acid analysis.

Table 1. Limit of detection and limit of quantitation

\begin{tabular}{lccccccc}
\hline Replication & Day 1 & Day 2 & Day 3 & Average & $\begin{array}{l}\text { Deviation } \\
\text { Standard }\end{array}$ & LOD & LOQ \\
\hline 1 & 0.004 & 0.003 & 0.012 & & & & \\
2 & 0.008 & 0.025 & 0.021 & & & & \\
3 & 0.007 & 0.035 & 0.007 & & & \\
4 & 0.014 & 0.016 & 0.003 & 0.0124 & 0.00964 & & \\
5 & 0.027 & 0.029 & 0.013 & & & \\
6 & 0.011 & 0.011 & 0.000 & & & \\
7 & 0.005 & 0.009 & 0.000 & & & \\
\hline
\end{tabular}

\section{Analysis of the food sample}

The food samples used in the boric acid analysis using in-situ matrix volatilization were sausages samples with five different brands. The boric acid concentration was measured by UV-Vis spectrophotometer at a wavelength of $555 \mathrm{~nm}$ using curcumin reagent. The boric acid content in 5 samples ranged from $0.913-3.518 \mathrm{mg} / \mathrm{kg}$. The highest concentration of boric acid is contained in the sausage brand D, which is $3.518 \mathrm{mg} / \mathrm{kg}$. It shows that boric acid and its derivatives are still used as food additives in food production, even though the measured content of boric acid varies among the sausage brands. The boric acid content in the tested food was also found to be different over time and the manufacturers by Yiu et al. (2008). Some producers apply boric acid concentration to food inconsistently because there was no exact measurement made by manufacturers. It was based on approximation by workers who handled the food production. Therefore different workers or manufacturers may add different amounts of boric acid. Moreover, different concentration of boric acid in food samples was caused by a lack of mixing food ingredients with boric acid (Yiu et al., 2008). 


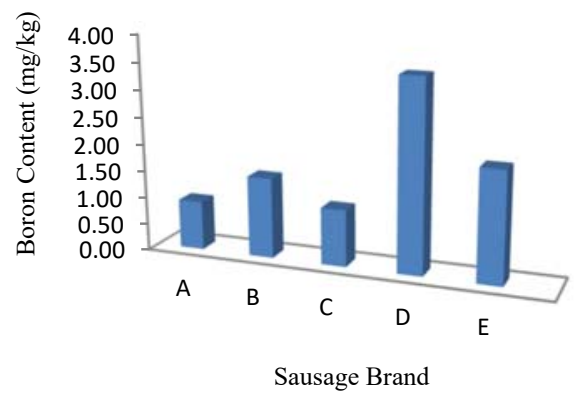

Figure 6. Boron content in sausages

\section{Conclusions}

Analyte separation by an in-situ volatilization system in a polytetrafluoroethylene (PTFE) container can be used for boric acid analysis in the food samples. It is recommended that the volatilization system can be conducted in a waterfree condition. The present volatilization system achieved the optimum condition when using curcumin concentration of $0.1 \%$ and ethanol:water ratio of 3:1. The results of LOD and LOQ determination exhibit that this method has detection limits and quantitation limits of 0.0413 $\mathrm{mg} / \mathrm{L}$ and $0.1088 \mathrm{mg} / \mathrm{L}$, respectively. The measured concentration of boric acid in sausage samples was found from 0.913 to $3.518 \mathrm{mg} / \mathrm{kg}$.

\section{References}

See, A. S., Salleh, A. B., Bakar, F. A., Yusof, N. A., Abdulamir, A. S., \& Heng, L. Y. (2010). Risk and health effect of boric acid. American Journal of Applied Sciences, 7(5), 620-627.

Adu, R. (2021). Spectrophotometric determination of boron in food products by ester borate distillation into curcumin. Journal of Chemistry, 15(1), 67-73.

Chaurasia, S. C., Sahayam, A. C., \& Mishra, R. K. (2002). Room-temperature isopiestic distillation of in situ generated arsenious chloride and its application for the determination of trace level impurities in arsenious oxide. Analytical Chemistry, 74(23), 6102-6105.

Crompton, T. R. (2000). Determination of organic compounds in soils, sediments, and sludges. London: CRC Press.

Dash, K., Thangavel, S., Dhavile, S. M., Rao, S. V., Chaurasia, S. C. \& Arunachalam, J. (2005). Vapor phase matrix extraction of high purity diboron trioxide and trace analysis using electrothermal AAS. Analytica Chimica Acta, 546(2), 229-235.

Dhavile, S. M., Thangavel, S., Chandrasekaran, K., Dash, K., Rao, S. V., \& Chaurasia, S. (2004). In situ matrix evaporation by isothermal distillation of high-purity reagents for the determination of trace impurities by ion chromatography. Journal of Chromatography $A$, 1050(2), 223-227.

Dyrssen, D. W., Novikov, Y. P., \& Uppstrom, L. R. (1972). Studies on the chemistry of the determination of boron with curcumin. Analytical Chimica Acta, 60(1), 139-151.

Hayes, M. R., \& Metcalfe, J. (1962). The boroncurcumin complex in the determination of trace amounts of boron. The Analyst, 87(1041), 956969.

Kabay, N., Güler, E., \& Bryjak, M. (2010). Boron in seawater and methods for its separation-A review. Desalination, 261(3), 212-217.

Litovitz, T. L., Klein-Schwartz, W., Oderda, G.M. \& Schmitz, B. F. (1988). Clinical manifestations of toxicity in a series of 784 boric acid ingestions. The American Journal of Emergency Medicine, 6(3), 209-213.

Molinero, A. L., Ferrer, A., \& Castillo, J. R., (1993). Volatilization of methyl borate in iron matrix determination of boron in steel by icp atomic emission spectrometry. Talanta, 40(9), $1397-$ 1403.

Park, C. J., \& Song, S., (2003). Determination of boron in high-purity sulfuric acid by ester generation and isotope dilution inductively coupled plasma mass spectrometry. Journal of Analytical Atomic Spectrometry, 18(10), 12481251.

Sahayam, A. C., Jiang, S. J., \& Wan, C. C., (2004). Determination of ultra-trae impurities in high purity gallium arsenide by inductively coupled plasma mass spectrometry after volatilization of matrix. Journal of Analytical Atomic Spectrometry, 19(3), 407-409.

San, S., Kyi, K. W., \& Naing, K., (2001). Spectrophotometric determination of boron in environmental water samples. Proceedings of the $15^{\text {th }}$ International Mass Spectrometry Conference (pp 201-208). Barcelona: Wiley.

Thangavel, S., Dash, K., Dhavile, S. M., Chaurasia, S.C. \& Mukherjee, T. (2005). Determination of traces of chloride and fluoride in $\mathrm{H}_{2} \mathrm{SO}_{4}$, $\mathrm{H}_{3} \mathrm{PO}_{4}$ and $\mathrm{H}_{3} \mathrm{BO}_{3}$ by in situ analyte 
distillation-ion chromatography. Journal of Chromatography A, 1074(1-2), 229-233.

Thangavel, S., Dhavile, S. M., Dash, K. \& Chaurasia, S. C. (2004). Spectrophotometric determination of boron in complex matrices by isothermal distillation of borate ester into curcumin. Analytica Chimica Acta, 502(2), 265-270.

Ueng, R-L., Sahayam, A. C., Jiang, S-J. \& Wan, CC. (2004). Microwave-assisted volatilization of chlorides of Ge and Se for the determination of trace impurities in high purity Ge and Se by ICP-MS. Journal of Analytical Atomic Spectrometry, 19(5), 681-684.

Yiu, P. H., See. J., Rajan, A., \&. Bong, C. F. J. (2008). Boric acid levels in fresh noodles and fish ball. American Journal of Agricultural and Biological Science, 3(2), 476-481. 